\title{
Análise de crescimento da gliricídia submetida a diferentes manejos de corte
}

\author{
Edvan, R.L. ${ }^{1}$; Carneiro, M.S. de S. ${ }^{2}$; da Silva, E.B. ${ }^{2}$; Albuquerque, D.R. ${ }^{2}$; Pereira, E.S. ${ }^{2}$; Bezerra, L.R. ${ }^{\text {'; }}$ da Silva A.L. ${ }^{1}$ \\ e de Araújo, M.J.'
}

'Universidade Federal do Piauí. Curso de Zootecnia. Bom Jesus-PI. Brasil.

2Universidade Federal do Ceará. Departamento de Zootecnia. Fortaleza-Ce. Brasil.

\section{PALAVRAS CHAVE ADICIONAIS}

Área foliar específica.

Gliricidia sepium.

Sequeiro.

Semiárido.

\section{RESUMO}

Objetivou-se avaliar as respostas de crescimento da Gliricídia sepium submetida a diferentes manejos de corte. O delineamento utilizado foi o de blocos ao acaso no esquema de parcelas subdivididas, em que a frequência de corte $(45,60,75$ e 90 dias) compreendeu a parcela principal e a altura de resíduo $(30,60$ e $90 \mathrm{~cm}$ ), a subparcela. A análise do crescimento foi obtida por meio da determinação da área foliar específica, índice de área foliar, taxa de crescimento relativo, taxa assimilatória líquida e taxa de crescimento da cultura, sendo avaliada também a produção de massa seca de folha/corte, massa seca de caule/corte, massa seca de folha total e massa seca de caule total. As plantas manejadas com frequência de corte de 90 dias obtiveram maior área foliar específica e índice de área foliar, o mesmo foi observado para altura de resíduo de $90 \mathrm{~cm}$. A maior taxa de crescimento cultural foi de $2,63 \mathrm{~g} / \mathrm{m}^{2}$. dia obtida no manejo de corte com frequência de 45 dias e altura de resíduo de $90 \mathrm{~cm}$. No mesmo manejo de corte observou-se o valor máximo para taxa de crescimento relativo de $0,016 \mathrm{~g}$ g-1 dia-1 e maior taxa assimilatória líquida de 1,32 $\mathrm{g} / \mathrm{m}^{2}$. dia. Ambas as taxas foram obtidas no período do $3^{\circ}$ ao $4^{\circ}$ corte (período chuvoso). Para o manejo de corte com frequência de 90 dias e altura observou-se maior produção de massa seca de folha e caule por corte e total. Na altura de resíduo de $90 \mathrm{~cm}$ houve maior produção de massa seca de folha e caule por corte e total. O manejo de corte influencia o crescimento e o acúmulo de massa de forragem da gliricídia de acordo com a precipitação pluvial da região.

\section{Growth analysis gliricidia under different cutting managements}

\section{SUMMARY}

The objective was to evaluate growth responses of Gliricídia sepium under different cutting managements. The statistical design was a randomized block design with split plots. The plots consisted of four cutoff frequencies $(45,60,75$ and 90 days) and three heights residue $(30,60$ and $90 \mathrm{~cm})$ with four replications, and the cut off frequency comprised the major portion of the residue height of the subplot. The analysis of growth was obtained through specific leaf area, leaf area index, relative growth rate, net assimilation rate and growth rate of the culture, and also evaluated the dry mass of leaves per cutting, stem dry weight by cutting, leaf dry mass and total dry mass of stem full. The plants managed with 90 days cutoff frequency had higher specific leaf area and leaf area index, the same was observed for $90 \mathrm{~cm}$ waste of time. The highest growth rate cultural was $2.63 \mathrm{~g} / \mathrm{m}^{2} \cdot$ dia obtained in the management of cutting frequency of 45 days and residue height of $90 \mathrm{~cm}$. At the same management cut off was observed for the maximum relative growth rate which was 0.016 g g-1 dia-1 and higher net assimilation rate with $1.32 \mathrm{~g} / \mathrm{m}^{2}$. dia, both rates were obtained in period of $3^{\circ}$ to $4^{\circ}$ cut (rainy season). For cutting management often 90 days and then observed a higher dry matter yield of leaf and stem by cutting and total. In the $90 \mathrm{~cm}$ height residue was higher dry matter yield of leaf and stem by cutting and total. The management of cut influences the growth and production of herbage mass of $G$. sepium, according to rainfall in the region.

\section{INTRODUÇÃO}

O cultivo de forrageiras em sequeiro é susceptível as variações climáticas, principalmente os localizados em região de clima tropical. É importante se analisar estratégias para esse ambiente (Suassuna et al., 2014). Neste contexto, Pilau et al. (2005) relataram que a disponibilidade e a qualidade da forragem são influenciadas pela espécie forrageira, propriedades do solo, condições climáticas, idade fisiológica e pelo manejo a que está submetida.
Segundo Fernandes et al. (2010), as forrageiras tropicais, de modo geral, apresentam grande concentração da produção de forragem durante a época das chuvas. Dessa forma, conhecer as possíveis interações desses fatores auxilia no manejo e na utilização das plantas forrageiras, objetivando a maximização da quantidade e qualidade da forragem produzida. Algumas espécies com metabolismo C3 possuem mecanismos de adaptação a regiões semiárida, como é caso da Gliricidia sepium leguminosa originária do México e difundida em boa parte da Amé- 
rica Latina, que apresenta rápido crescimento, resistência à seca e alta capacidade de rebrota (Drumond Filho and Carvalho, 1999), principalmente por possuir raiz pivotante profunda.

A utilização de bancos forrageiros de leguminosas é alternativa eficiente para reduzir o déficit alimentar dos animais no período seco do ano (Mororó et al., 2010). As leguminosas cultivadas em pastagens e em bancos de proteína contribuem na correção da deficiência de proteína na alimentação animal, fornecendo forragem de melhor qualidade, desde que a concentração de compostos antinutricionais, como os taninos, não comprometa a capacidade digestória do animal.

A Gliricidia sepium é uma espécie de grande interesse comercial e econômico para regiões tropicais pelas suas características de uso múltiplo, sendo assim, uma espécie forrageira com grande potencial para região semiárida brasileira. Costa et al. (2009) relataram o uso desta espécie na alimentação animal principalmente de bovinos, caprinos e ovinos. Morales (1996) avaliou a gliricídia e encontrou valor médio de proteína bruta de $22 \%$. Dessa forma, é importante obter informações do crescimento da gliricídia durante o ano, em relação ao manejo de corte empregado e das variáveis climáticas, em especial, a precipitação pluviométrica.

Diante do exposto, esse trabalho foi desenvolvido com objetivo de avaliar as respostas morfofisiológicas da gliricídia submetida a diferentes manejos de corte.

\section{MATERIAL E MÉTODOS}

O experimento foi desenvolvido no município Fortaleza, Ceará, no Setor de Forragicultura do Departamento de Zootecnia da Universidade Federal do Ceará (UFC), no período de março de 2010 a dezembro de 2011, A região é situado na Zona Litorânea, a $21 \mathrm{~m}$ de altitude. Segundo a classificação de Köppen, o clima é do tipo Aw, tropical chuvoso, com chuvas principalmente no verão, com precipitação pluviométrica distribuída no período de janeiro a abril.

O solo utilizado foi classificado como Argissolo Vermelho-Amarelo com as seguintes características químicas: 9 $\mathrm{mg} / \mathrm{dm}^{3}$ de $\mathrm{P} ; 70 \mathrm{mg} / \mathrm{dm}^{3}$ de $\mathrm{K} ; 3,5 \mathrm{cmol}_{\mathrm{c}} / \mathrm{dm}^{3}$ de Ca + $\mathrm{Mg} ; 0 \mathrm{cmol}_{\mathrm{c}} / \mathrm{dm}^{3}$ de Al; $1,9 \mathrm{cmol}_{\mathrm{c}} / \mathrm{dm}^{3} \mathrm{de} \mathrm{Ca} ; 1,6 \mathrm{cmol}_{\mathrm{c}} /$ $\mathrm{dm}^{3}$ de $\mathrm{Mg} ; 8 \mathrm{cmol}_{\mathrm{c}} / \mathrm{dm}^{3}$ de $\mathrm{Na}$; e pH em $\mathrm{H}_{2} \mathrm{O}$ de 6,1.

Os dados de temperatura e precipitação pluviométrica (figura 1) foram registrados pela estação meteorológica da UFC localizada á aproximadamente $600 \mathrm{~m}$ do local do experimento, durante o período de avaliação do experimento, o acúmulo médio da precipitação pluviométrica no período de avaliação (dezembro 2011 a dezembro de 2012) foi de $1030,50 \mathrm{~mm}$. A temperatura oscilou pouco durante o ano, a média para o período experimental foi de $27,5^{\circ} \mathrm{C}$, a menor temperatura registrada neste período foi no mês de abril de 2011 de $26,2^{\circ} \mathrm{C}$ e a maior no mês de novembro de 2011 de $29,6^{\circ} \mathrm{C}$.

O delineamento estatístico utilizado foi de blocos ao acaso em esquema de parcelas subdivididas. As parcelas constaram de quatro frequências de corte $(45,60,75$ e 90 dias) e três alturas de resíduo $(30,60$ e 90 cm) com quatro repetições, em que a frequência de corte compreendeu a parcela principal e altura de resíduo, a subparcela.

A área experimental utilizada foi de $600 \mathrm{~m}^{2}$ com estande de 336 plantas. Foram avaliadas quatro plantas úteis por subparcela, a qual foi separada por linhas de bordaduras. Não foi necessário fazer correção no solo por ocasião do plantio, que foi realizado em março de 2010, com estacas de Gliricidia sepium retiradas de árvores com quatro anos de idade, locadas no Centro de Ciências Agrárias da UFC. As estacas foram padronizadas com diâmetro médio de 3 a $5 \mathrm{~cm}, 20 \mathrm{~cm}$ de comprimento contendo oito gemas cada e plantadas em espaçamento de 1,5 m x 1,0 m. O plantio das estacas foi diretamente no solo, quando o mesmo estava úmido e devido aos períodos de estiagem, comum na região, as plantas foram irrigadas com $3 \mathrm{~L}$ de água por planta, sempre que necessário até constatação da pega das estacas que ocorreu no primeiro mês do plantio, após esse período não foi mais realizado irrigação.

O período experimental foi de 620 dias, sendo 245 dias de estabelecimento da cultura e 375 dias de avaliação das características de produção. O corte de uniformização com a aplicação dos tratamentos foi realizado em dezembro de 2010 ( $246^{\circ}$ dia) quando, aproximadamente, $80 \%$ das plantas atingiram 1,5 m da superfície do solo. A quantidade de cortes variou de acordo com o tratamento, obtendo-se $8,6,5$ e 4 cortes para os tratamentos com as frequências de corte 45, 60, 75 e 90 dias, respectivamente. As plantas de gliricídia foram adubadas com $90 \mathrm{~kg} / \mathrm{ha}$ de fosfato (superfosfato simples) e $60 \mathrm{~kg} /$ ha de potássio (cloreto de potássio). Optou por não realizar a adubação nitrogenada para não inibir a fixação biológica de nitrogênio, que é umas das principais vantagens do plantio de espécies da família das leguminosas.

A análise do crescimento foi realizada por meio da mensuração da área foliar específica (AFE), índice de área foliar (IAF), taxa de crescimento relativo (TCR), taxa assimilatória líquida (TAL) e taxa de crescimento da cultura (TCC). Também foram avaliadas a produção de massa seca de folha por corte (MSFC), massa seca de caule por corte (MSCC), massa seca de folha total (MSFT) e massa seca de caule total (MSCT), a massa seca total obteve-se através dos somatórios dos cortes.

Em cada corte, o material colhido foi pesado no campo, para se obter o total de massa verde. Em seguida, uma amostra com cerca de $500 \mathrm{~g}$ da massa verde foi retirada para determinação da massa seca. Nessa amostra foi realizada a separação do material potencialmente comestível pelo animal (folhas e caules com espessura máxima de 1,0 $\mathrm{cm}$ ) do material lenhoso que foram considerados os caules com espessura superior a 1,0 cm. Após a separação, as amostras foram secas em estufa de circulação e renovação de ar, em temperatura de $55^{\circ} \mathrm{C}$, até peso constante, obtendo-se a matéria seca da folha e do caule.

Os dados para calcular a área foliar foram obtidos através do método dos quadrados, utilizando material transparente quadriculado $(1,0 \mathrm{~m} \times 1,0 \mathrm{~m})$, contendo 100 quadrados $\left(1,0 \mathrm{~cm}^{2}\right)$. O material foi colocado sobre as folhas e contou-se o número de quadrados envolvidos pelo contorno das folhas. Calculou-se então, $\mathrm{m}^{2}$ de folha por $\mathrm{m}^{2}$ de terreno, para se obter o IAF. AAFE foi estimada por meio da fórmula: AFE $=$ Af $/ \mathrm{Pf}\left(\mathrm{cm}^{2} / \mathrm{g}\right)$, onde Af = área da folha e Pf = peso de massa seca da folha. 
Calculou-se a TCC, TCR e a TAL, conforme Benincasa (2003): TCC $=\{\mathrm{P} 2-\mathrm{P} 1 / \mathrm{dT} / \mathrm{As}\}\left(\mathrm{g} / \mathrm{m}^{2} \cdot \mathrm{dia}\right)$, onde P1 = peso de fitomassa seca no corte anterior, $\mathrm{P} 2$ = peso de fitomassa seca no corte, $\mathrm{dT}=$ intervalo de tempo entre as coletas dia e $\mathrm{As}=\mathrm{m}^{2}$ de solo; $\mathrm{TCR}=[\mathrm{P} 2-\mathrm{P} 1 /(\mathrm{P} 2-\mathrm{P} 1 / 2)] /$ $\mathrm{dT}$ (g g-1 dia-1), onde: onde P1 = peso de fitomassa seca no corte anterior, $\mathrm{P} 2$ = peso de fitomassa seca no corte $\mathrm{e}$ $\mathrm{dT}=$ intervalo de tempo entre as coletas dia; $\mathrm{TAL}=\{[(\mathrm{P} 2$ -P1)/(Af 2-Af1)/2]/dT\} $\left(\mathrm{g} / \mathrm{m}^{2} \cdot\right.$ dia $)$, onde P1 = peso de fitomassa seca no corte anterior, P2 = peso de fitomassa seca no corte, Af1 = área da folha no momento do corte anterior, Af2 = área da folha no momento do corte e dT = intervalo de tempo entre as coletas dia.

Os resultados das variáveis AFE, IAF, MSFC e MSCC foram as médias de cada intervalo de corte (ciclos), para MSFT e MSCT os dados foram agrupados em único período e submetidas à análise de variância, utilizando-se o software SISVAR versão 5.0, desenvolvido pela Universidade Federal de Lavras (Ferreira, 2011). A comparação de médias foi realizada através do teste de Tukey, adotando-se $5 \%$ de nível de significância. Os resultados das variáveis TCC, TCR e TAL foram analisadas por corte e descritos em gráficos com média e respectivo desvio-padrão.

\section{RESULTADOS E DISCUSSÃO}

Não houve efeito $(p>0,05)$ para a interação para frequência de corte e altura de resíduo em nenhuma das variáveis. Para área foliar específica (AFE) houve efeito significativo apenas para frequência de corte. Em relação ao índice de área foliar (IAF), massa seca de folha por cote massa seca de folha por corte (MSFC), massa seca de caule por corte (MSCC), massa seca de folha total (MSFT) e massa seca de caule total (MSCT) observou-se efeito significativo para frequência de corte e altura de resíduo (tabela I).

A frequência de corte 90 dias obteve maior valor de AFE (tabela II). Esse fato pode estar relacionado à maior permanência destes tratamentos no campo que permitiu crescimento foliar superior as outras frequências de corte, devido, principalmente, ao maior aproveitamento das precipitações pluviais que ocorreram no período de avaliação (figura 1). Segundo Parsons and Chapman (2000) a expansão celular, a qual requer pressão hídrica, é mais sensível ao estresse hídrico que a divisão celular. Lopes et al. (2000) avaliando as características morfofisiológicas da Leucena (Leucaena leucocephala) em duas épocas do ano, verificaram que o maior crescimento das plantas foi obtido na época chuvosa.

Para as frequências de corte 45, 60 e 75 dias, verificou-se os menores valores para AFE, esse fato indica que a maior frequência de corte na gliricídia proporcionou menor crescimento na folha. Perez and Fanti (1999), avaliando o crescimento e a resistência à seca de leucena (Leucaena leucocephala Lam.) em solo de cerrado no estado de São Paulo, relataram que a área foliar específica é um componente morfológico que oscila bastante, com o decorrer do ano. As diferentes frequências de corte proporcionam diferente período de coletas da forragem em períodos com diferentes acúmulo de chuva, fornecendo uma variação entre elas, sendo que com maior

Tabela I. Resumo da análise de variância da Gliricidia sepium em relação à frequência de corte e altura de resíduo (Summary of Gliricidia sepium variance analysis in relation to the cutoff frequency and the residue height).

\begin{tabular}{llllllll}
\hline \multirow{2}{*}{ FV } & \multicolumn{7}{c}{ Quadrado Médio } \\
\cline { 2 - 8 } & GL & AFE & IAF & MSFC & MSCC & MSFT & MSCT \\
\hline Bloco & 3 & $15,95^{*}$ & $2,15^{*}$ & $8224,8^{*}$ & $2615,7^{*}$ & $206751,1^{*}$ & $63576,7^{*}$ \\
Frequência & 3 & $84,42^{*}$ & $12,59^{*}$ & $50959,3^{*}$ & $18600,4^{*}$ & $281319,1^{*}$ & $113882,1^{*}$ \\
Altura & 2 & $1,61^{\text {ns }}$ & $13,52^{*}$ & $52897,9^{*}$ & $16014,1^{*}$ & $1354840,5^{*}$ & $414131,5^{*}$ \\
F x A $^{9}$ & 6 & $10,14^{\text {ns }}$ & $1,98^{\text {ns }}$ & $6426,25^{\text {ns }}$ & $1655,92^{\text {ns }}$ & $58630,3^{\text {ns }}$ & $13788,9^{\text {ns }}$ \\
CV $^{10}(\%)$ & & 4,41 & 42,86 & 42,56 & 37,46 & 42,89 & 41,17 \\
\hline
\end{tabular}

FV: Fonte de variação, GL: grau de liberdade, AFE: área foliar específica; IAF: índice de área foliar, MSFC: massa seca de folha por corte, MSCC: massa seca de caule por corte, MSFT: massa seca de folha total, MSCT: massa seca de caule total, F x A: interação entre a frequência de corte e altura de resíduo, CV: coeficiente de variação.

*: significativo a $5 \%$ de probabilidade, ns: não significativo a $5 \%$ de probabilidade.

Tabela II. Crescimento foliar de gliricídia em relação às frequências de corte e altura de resíduo (Gliricidia sepium leaf growth in relation to the cutting frequencies and residue height).

\begin{tabular}{|c|c|c|c|c|c|}
\hline & \multicolumn{4}{|c|}{ Frequência de corte (dias) } & \multirow{2}{*}{ EPM } \\
\hline & 45 & 60 & 75 & 90 & \\
\hline $\operatorname{AFE}\left(\mathrm{cm}^{2} / \mathrm{g}\right)$ & $44,59^{b}$ & $44,15^{b}$ & $43,47^{b}$ & $47,74^{a}$ & 0,588 \\
\hline \multirow[t]{3}{*}{ IAF } & $1,33^{b}$ & $1,71^{\mathrm{b}}$ & $2,26^{b}$ & $3,67^{a}$ & 0,278 \\
\hline & \multicolumn{4}{|c|}{ Altura de resíduo $(\mathrm{cm})$} & \multirow{2}{*}{ EPM } \\
\hline & 30 & 60 & \multicolumn{2}{|r|}{90} & \\
\hline AFE $\left(\mathrm{cm}^{2} / \mathrm{g}\right)$ & $\frac{30}{46,54^{a}}$ & $46,26^{a}$ & \multicolumn{2}{|r|}{$45,91^{a}$} & 0,509 \\
\hline $\mathrm{IAF}$ & $1,32^{c}$ & $2,23^{\mathrm{b}}$ & \multicolumn{2}{|r|}{$3,18^{a}$} & 0,241 \\
\hline
\end{tabular}

AFE: Área específica da folha; IAF: índice de área foliar.

a,b,cMédias com mesma letra minúscula na linha, não diferem entre si pelo teste de Tukey, ao nível de 5\% probabilidade; EPM: erro-padrão da média. 
permanência no campo a planta tem maior capacidade de ser manter em crescimento.

A altura de resíduo de $90 \mathrm{~cm}$ proporcionou maior IAF na gliricídia, demonstrando que maior intensidade de corte, prejudica o seu crescimento. Nesta pesquisa, as precipitações pluviais irregulares associadas a um manejo intenso promoveram redução no crescimento da gliricídia (figura 1). Neste contexto, Noy-Meir (1973) relatou que enquanto a temperatura, a radiação solar e os aportes de nutrientes nos ecossistemas do semiárido variam relativamente pouco durante o ano, a precipitação comumente ocorre em eventos descontínuos. Na região do estudo a irregularidade da precipitação pluvial foi acentuada nos 135 dias finais do período de avaliação (figura 1A), fato que influenciou o crescimento da Gliricídia, essa irregularida pluvial é comum na região (figura 1B).

É importante observar que o IAF serve como indicador da cobertura foliar do terreno e que o IAF máximo não é onde se obtém maior produção de fitomassa, pois, segundo Peixoto et al. (2011), quando água e nutrientes não são limitantes, o IAF poderá facilmente exceder o seu ótimo sem, contudo, significar maior aumento em fitomassa. Chaves et al. (2007) encontraram para a dinâmica do dossel do eucalipto que o índice de área foliar foi maior no período chuvoso, evidenciando a rápida recomposição da planta após o corte com o início das chuvas.

O maior IAF obtido para a frequência de corte de 90 dias foi de 3,67 e para altura de resíduo de $90 \mathrm{~cm}$ com 3,18. Fisher \& Cruz (1994) mostraram que o Arachis pintoi quando em monocultivo atingiu índice de área foliar (IAF) acima de 3 em duas semanas de crescimento. Oliveira et al. (2000) avaliando o crescimento do capim Tifton 85 (Cynodon spp.) encontraram valores máximos estimado de IAF de 4,9 aos 47 dias. Esses valores de IAF obtidos na gliricídia indicam que em leguminosas o IAF ótimo é menor que os encontrados nas gramíneas devidos a posicionamento das folhas. As leguminosas, por apresentarem as folhas na posição horizontal, são capazes de interceptarem mais luz por unidade de área foliar do que as gramíneas com suas folhas semi-eretas (Costa et al., 2008). O IAF ótimo da gliricídia é em torno de 3,18 (tabela II) que ocorre com a frequência de 90 dias quando a planta apresenta maior acúmulo de folhas, outro fato é que na gliricídia ocorre a abscisão foliar e não senescência foliar, dessa forma seria difícil obter IAF superiores como nas gramíneas.

As taxas de crescimento cultural (TCC) observadas no período do $1^{\circ}$ ao $2^{\circ}$ cortes foram inferiores para maioria dos manejos empregados, sendo que os manejos com frequência de corte de 60 dias e 90 dias combinados com altura de resíduo de $60 \mathrm{~cm}$ e $90 \mathrm{~cm}$ as TCC's foram positivas, porém com valores baixos (figura 2), indicando a influência da frequência e intensidade de corte na TCC. Gama et al. (2009) avaliando frequência de corte em Gliricidia sepium e Leucaena leucocephala constataram que nenhuma das espécies alcançou no segundo corte o crescimento obtido no primeiro. Provavelmente após o corte de padronização as reservas residuais são suficientes para repor a parte aérea o que não ocorre no corte subsequente, principalmente em corte mais intensos. Esse

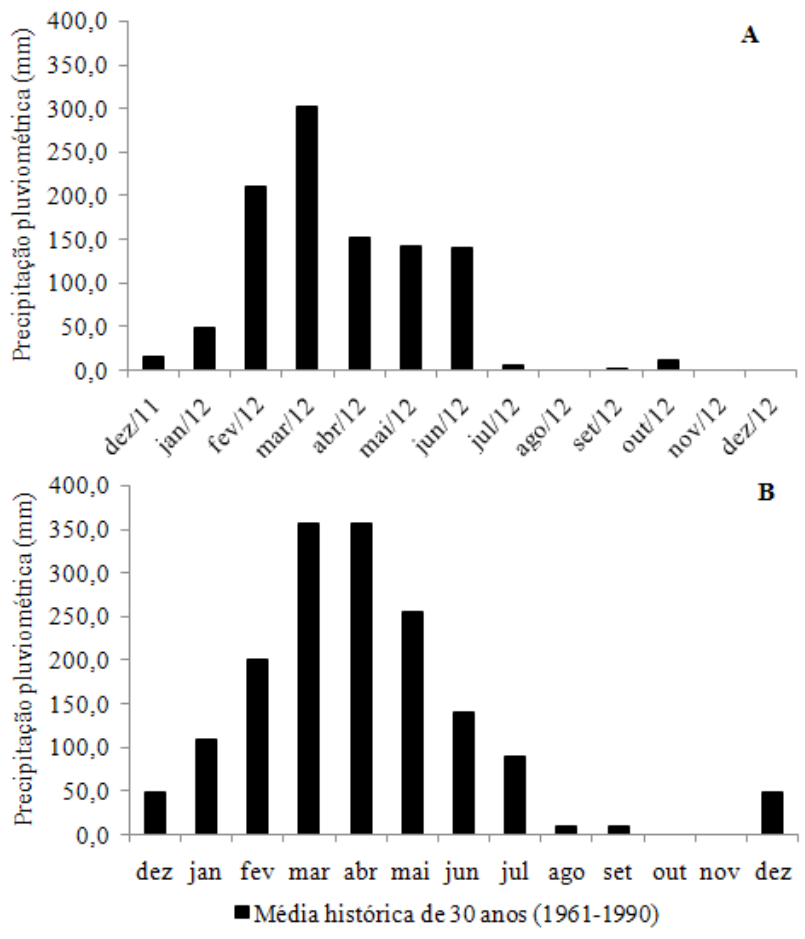

Figura 1. Precipitação pluvial registradas no período de análise experimental em Fortaleza, Ceará -Gráfico A. Média histórica da precipitação pluvial registradas em Fortaleza, Ceará - Gráfico B (Rainfall logged in the experimental analysis period in Fortaleza, Ceará - Graphic A. Historical average rainfall registered in the Fortaleza, Ceará Graphic B). Fonte: Instituto Nacional de Meteorologia - INMET. Estação: 81758 - Fortaleza - CE.

fato ocorre em plantas arbóreas que necessitam de maior tempo para se desenvolver e para se adaptar ao manejo de corte, diferentemente, do que é observado no crescimento das gramíneas que tem uma rápida reposição de suas reservas. Kanieski et al. (2012) avaliando a influência da precipitação e temperatura no crescimento de espécies florestais, observaram que o crescimento é sazonal, com picos em meses diversos.

As maiores taxas foram obtidas para frequência de corte de 45 dias no período do $3^{\circ}$ ao $4^{\circ}$ ciclo e para as frequências 60, 75 e 90 dias no período do $2^{\circ}$ ao $3^{\circ}$ ciclo de corte. Esse fato provavelmente está associado ao período em que os cortes foram realizados. Após esse período houve uma redução no crescimento para os tratamentos, onde o último corte apresentou as menores taxas de crescimento, que foi realizado no período seco do ano.

A maior TCC obtida foi para o manejo de corte com frequência de 45 dias e altura de resíduo de $90 \mathrm{~cm}$ de 2,63 $\mathrm{g} \mathrm{m}^{-2} \mathrm{dia}^{-1}$ no período do $3^{\circ}$ ao $4^{\circ}$ ciclo (período chuvoso) e a menor para frequência de corte de 90 dias e altura de resíduo de $60 \mathrm{~cm}$ com taxa negativa de $3,41 \mathrm{~g} \mathrm{~m}^{-2} \mathrm{dia}^{-1}$ no período do $3^{\circ}$ ao $4^{\circ}$ ciclo (período seco). O manejo de corte com altura de resíduo $90 \mathrm{~cm}$ apresentou maior número de TCC positiva em relação ao tempo, indicando que corte intenso prejudica o desenvolvimento da gliricídia.

De acordo com a figura $3 \mathbf{A}$, observou-se que a frequência de corte de 45 dias proporcionou maior variação na taxa de crescimento relativo (TCR) para as diferentes intensidades de corte. Os manejos de corte com intensidade de $90 \mathrm{~cm}$ obtiveram TCR's maiores que as plantas manejadas com altura de resíduo de 30 e $60 \mathrm{~cm}$. O valor máximo para TCR foi de $0,016 \mathrm{~g} \mathrm{~g}^{-1} \mathrm{dia}^{-1}$ observada no 



Figura 2. Taxa de crescimento cultural (TCC) da gliricídia submetida a diferentes manejos e acúmulo da precipitação pluviométrica em cada intervalo de corte (Cultural growth rate of Gliricidia sepium under different managements and accumulation of rainfall in each cutting interval).

A: frequência de corte 45 dias combinado com alturas de resíduo de 30,60 e $90 \mathrm{~cm}$; B: frequência de corte 60 dias combinado com alturas de resíduo de 30, 60 e $90 \mathrm{~cm}$; C: frequência de corte 75 dias combinado com alturas de resíduo de 30, 60 e $90 \mathrm{~cm}$; D: frequência de corte 75 dias combinado com alturas de resíduo de 30,60 e $90 \mathrm{~cm}$.

manejo com frequência de corte de 45 dias e altura de resíduo de $90 \mathrm{~cm}$ no período do $3^{\circ}$ ao $4^{\circ}$ corte (período chuvoso). A menor TCR foi constatada no manejo com frequência de corte de 45 dias e altura de resíduo de $30 \mathrm{~cm}$ no período do $1^{\circ}$ ao $2^{\circ}$ corte (período chuvoso) com taxa negativa de $0,018 \mathrm{~g} \mathrm{~g}^{-1} \mathrm{dia}^{-1}$. Esse fato demonstra a influência da intensidade de corte no crescimento da gliricídia, onde o corte mais intenso prejudicou o desenvolvimento da planta, mesmo com disponibilidade hídrica (período chuvoso). Vale salientar que variações na TCR podem ser decorrentes das diferenças genéticas entre espécies e variedades, do estádio de desenvolvimento da planta e, também, das condições climáticas (Oliveira et al., 2000), além do manejo empregado.

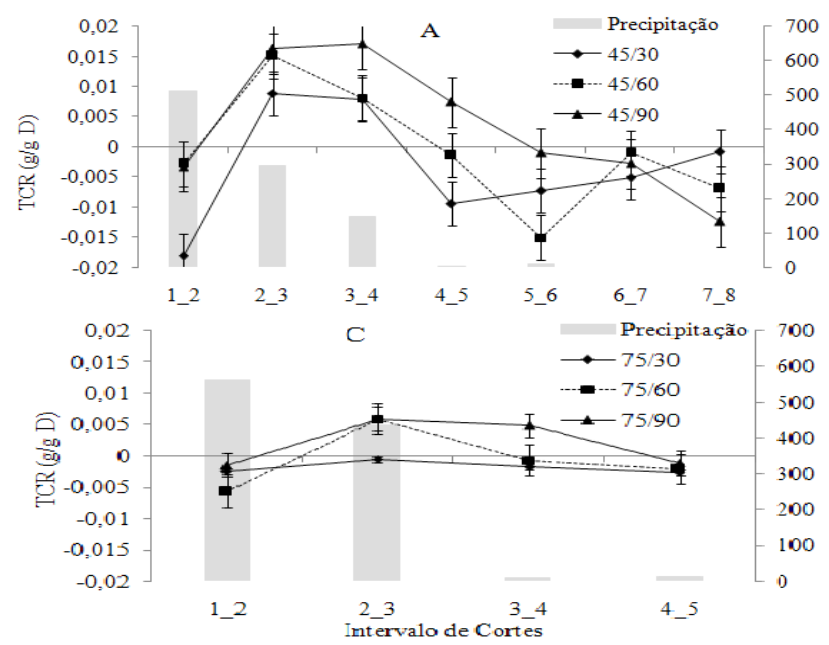

O corte associado à disponibilidade hídrica proporcionou aumento na taxa assimilatória líquida (TAL). Porém, no período de estiagem ocorreu decréscimo na TAL, independente do manejo empregado (figura 4). A frequência de 45 dias proporcionou maiores diferenças entre os ciclos de avaliação para TAL, demonstrando que o corte estimula o crescimento da planta de acordo com a precipitação pluviométrica do período. Notou-se que para frequência de 90 dias houve uma pequena variação entre as TALs, em consequência do período entre corte ter sido maior a planta obteve menor variação no seu crescimento entre os ciclos.

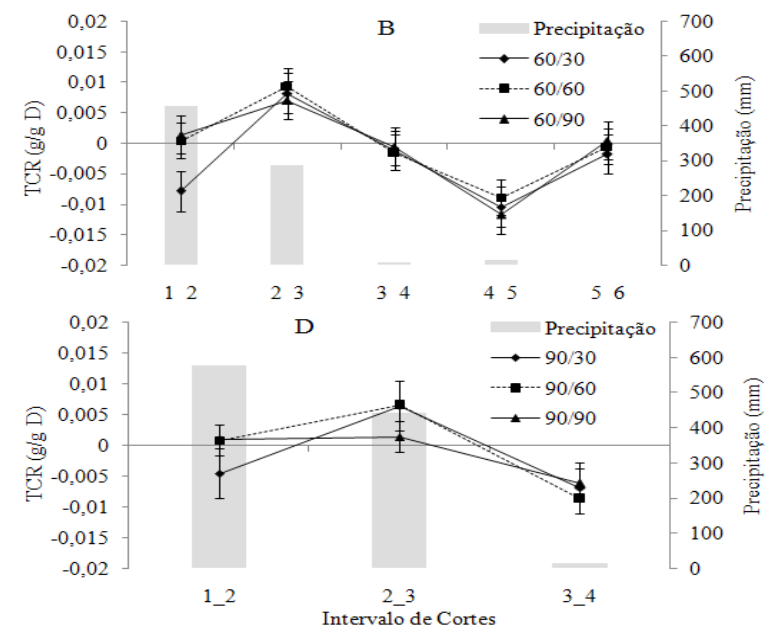

Figura 3. Taxa de crescimento relativo (TCR) da gliricídia submetida a diferentes manejos e acúmulo da precipitação pluviométrica em cada intervalo de corte (Relative growth rate of Gliricidia sepium under different managements and accumulation of rainfall in each cutting interval).

A: frequência de corte 45 dias combinado com alturas de resíduo de 30, 60 e 90 cm; B: frequência de corte 60 dias combinado com alturas de resíduo de 30, 60 e $90 \mathrm{~cm}$; C: frequência de corte 75 dias combinado com alturas de resíduo de 30 , 60 e 90 cm; D: frequência de corte 75 dias combinado com alturas de resíduo de 30,60 e $90 \mathrm{~cm}$. 
A maior TAL foi obtida para frequência de corte de 45 dias e altura de resíduo de $90 \mathrm{~cm}$ no período do $3^{\circ}$ ao $4^{\circ}$ ciclo (período chuvoso) com $1,32 \mathrm{~g} / \mathrm{m}^{2}$.dia e a menor com taxa negativa de $1,38 \mathrm{~g} / \mathrm{m}^{2} \cdot$ dia no período $7^{\circ}$ ao $8^{\circ}$ ciclo (período seco) no mesmo manejo. De acordo com Perez and Fanti (1999), a taxa assimilatória líquida diminui com o tempo, devido ao processo de senescência e abscisão foliar. No caso deste experimento, o tempo é referente aos períodos de cada corte, onde a irregularidade na precipitação pluviométrica afetou o crescimento da gliricídia e as folhas apresentaram abscisão e não senescência. Segundo Watson et al. (1966), a redução na TAL ocorre, principalmente, devido à redução na taxa fotossintética, fato que está relacionado diretamente com a produção de folhas da gliricídia que obteve respostas semelhantes aos da TAL durante o ano.

Em relação à frequência de corte houve efeito significativo para a produção de massa seca de folha por corte (MSFC) e total (MSFT) e para massa seca de caule por corte (MSCC) e total (MSCT), sendo que a frequência de 90 dias obteve os maiores valores apresentando 217,8, 127,1, 871,3 e 508,4 $\mathrm{g} \mathrm{m}^{-2}$, respectivamente. Essa frequência de corte obteve $32,29 \%$ e $37,93 \%$ a mais para produção de massa seca de folha e caule total, respectivamente, quando comparada com a frequência de corte de 45 dias. Esse fato demonstra que intervalo de corte longo proporciona maior acúmulo de massa de forragem de folha e caule na gliricídia.

Para altura de resíduo, a gliricídia apresentou efeito significativo para a produção de folha e colmo (tabela III), sendo que o resíduo de $90 \mathrm{~cm}$ proporcionou maiores produção. A elevada intensidade de corte (altura de resíduo $30 \mathrm{~m}$ ) proporcionou perda de 61,09\% na produção de folha e de 59,49\% na produção de caule de gliricídia quando comparada com a altura de resíduo de $90 \mathrm{~cm}$, demonstrando que elevada intensidade de corte diminui a produção da gliricídia, provavelmente devido a rebrota mais demorada para a intensidade de corte de 30 e $60 \mathrm{~cm}$.
A produção de massa de forragem total média da frequência de corte de 90 dias com a altura de corte de 90 cm foram 1379,7 e 1489,9 g/ m².ano, respectivamente. Esse fato demonstra que a intensidade tem maior influência que a frequência de corte para gliricídia. Esses valores são superiores ao obtido por Barretos and Fernandes (2001), ao cultivem Gliricidia sepium e Leucaena leucocephala em alamedas visando à melhoria dos solos dos tabuleiros costeiros, em que relataram produção média de 487 e 580 $\mathrm{g} / \mathrm{m}^{2}$ da parte aérea por ano para leucena e gliricídia, respectivamente.

Tabela III. Características produtivas da gliricídia em relação à frequência de corte e altura de resíduo (Gliricidia sepium production characteristics in relation to the cutoff frequency and residue height).

\begin{tabular}{llllll}
\hline & \multicolumn{5}{c}{ Frequência de corte (dias) } \\
\cline { 2 - 5 } & 45 & 60 & 75 & 90 & \\
\hline${ }^{1} \mathrm{MSFC}\left(\mathrm{g} \mathrm{m}^{-2}\right)$ & $73,7^{\mathrm{b}}$ & $86,3^{\mathrm{b}}$ & $126,5^{\mathrm{b}}$ & $217,8^{\mathrm{a}}$ & 15,4 \\
${ }^{2} \mathrm{MSCC}\left(\mathrm{g} \mathrm{m}^{-2}\right)$ & $39,4^{\mathrm{c}}$ & $48,4^{\mathrm{bc}}$ & $72,3 \mathrm{~b}$ & $127,1^{\mathrm{a}}$ & 7,7 \\
${ }^{3} \mathrm{MSFT}\left(\mathrm{g} \mathrm{m}^{-2}\right)$ & $590,0^{\mathrm{ab}}$ & $517,8^{\mathrm{b}}$ & $632,6^{\mathrm{ab}}$ & $871,3^{\mathrm{a}}$ & 80,8 \\
${ }^{4} \mathrm{MSCT}\left(\mathrm{g} \mathrm{m}^{-2}\right)$ & $315,6^{\mathrm{b}}$ & $290,6^{\mathrm{b}}$ & $361,6^{\mathrm{ab}}$ & $508,4^{\mathrm{a}}$ & 43,8 \\
\hline & Altura de resíduo $(\mathrm{cm})$ & & EPM \\
& 30 & 60 & 90 & & \\
\hline${ }^{1} \mathrm{MSFC}\left(\mathrm{g} \mathrm{m}^{-2}\right)$ & $69,8^{\mathrm{c}}$ & $123,6^{\mathrm{b}}$ & $184,7^{\mathrm{a}}$ & 13,4 \\
${ }^{2} \mathrm{MSCC}\left(\mathrm{g} \mathrm{m}^{-2}\right)$ & $42,0^{\mathrm{c}}$ & $68,4^{\mathrm{b}}$ & $105,0^{\mathrm{a}}$ & 6,7 \\
${ }^{3} \mathrm{MSFT}\left(\mathrm{g} \mathrm{m}^{-2}\right)$ & $370,3^{\mathrm{c}}$ & $636,8^{\mathrm{b}}$ & $951,6^{\mathrm{a}}$ & 70,0 \\
${ }^{4} \mathrm{MSCT}\left(\mathrm{g} \mathrm{m}^{-2}\right)$ & $218,1^{\mathrm{b}}$ & $350,7^{\mathrm{b}}$ & $538,3^{\mathrm{a}}$ & 37,9 \\
\hline
\end{tabular}

${ }^{1} \mathrm{MSFC}$ : Produção de massa seca de folha por corte, ${ }^{2} \mathrm{MSCC}$ : massa seca de caule por corte, ${ }^{3} \mathrm{MSFT}$ : massa seca de folha total e ${ }^{4} \mathrm{MSCT}$ : massa seca de caule total.

a,b,ccMédias com mesma letra minúscula na linha, não diferem entre si pelo teste de Tukey, ao nível de $5 \%$ probabilidade; EPM: erropadrão da média.
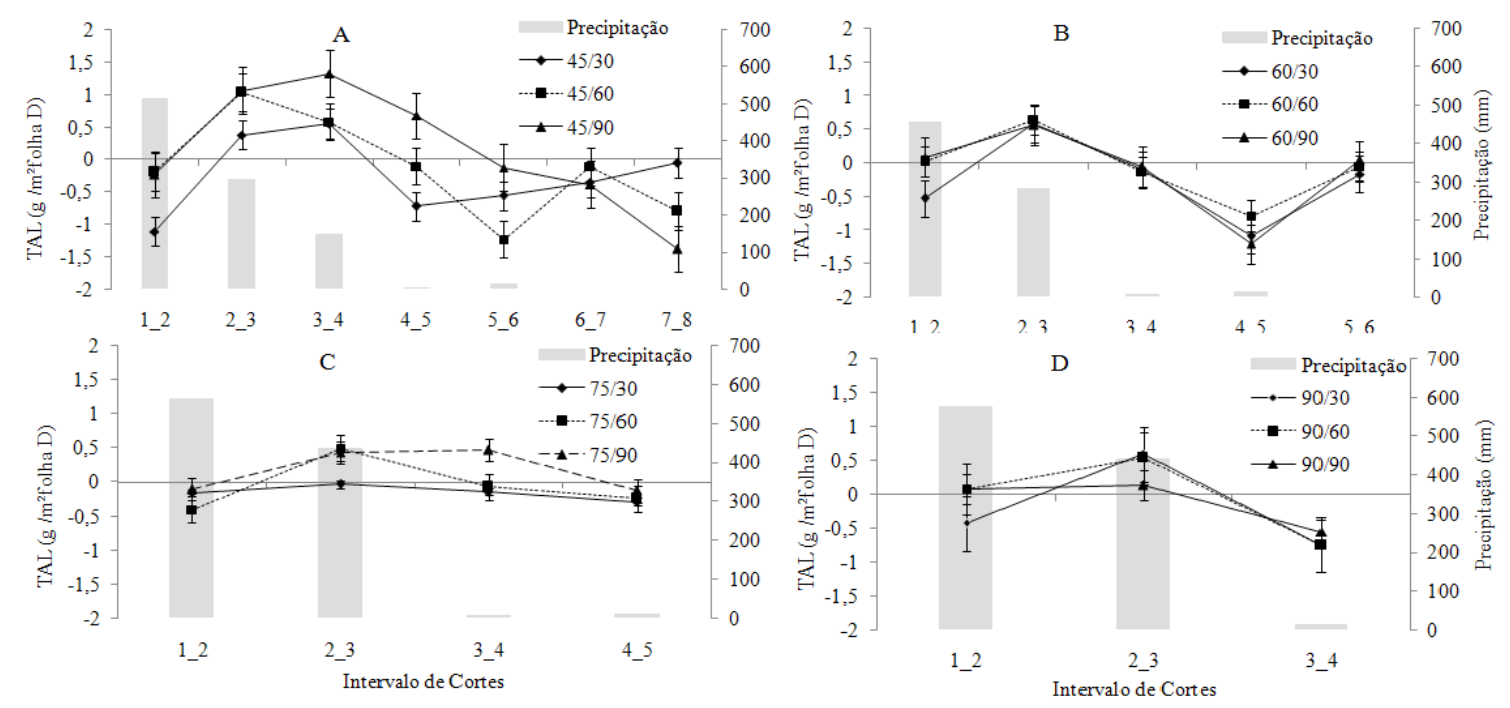

Figura 4. Taxa assimilatória líquida (TAL) da gliricídia submetida a diferentes manejos e acúmulo da precipitação pluviométrica em cada intervalo de corte (Net assimilation rate of Gliricidia sepium under different managements and accumulation of rainfall in each cutting interval).

A: Frequência de corte 45 dias combinado com alturas de resíduo de 30,60 e $90 \mathrm{~cm}$; B: frequência de corte 60 dias combinado com alturas de resíduo de 30, 60 e $90 \mathrm{~cm}$; C: frequência de corte 75 dias combinado com alturas de resíduo de 30,60 e $90 \mathrm{~cm}$; D: frequência de corte 75 dias combinado com alturas de resíduo de 30,60 e $90 \mathrm{~cm}$. 
A proporção da quantidade de folhas em relação à fitomassa foi de $63,15 \%$ para a frequência de 90 dias e de $63,8 \%$ para altura de resíduo de $90 \mathrm{~cm}$. Valores semelhantes aos descritos por Speedy and Pugliese (1991) que relataram que as folhas representam de 53 a $63 \%$ da fitomassa de gliricídia produzida.

Observou-se maiores produções de folha e caule para o manejo de corte de 90 dias e altura de resíduo de 90 $\mathrm{cm}$, demonstrando que o manejo frequente e intenso não é adequado para a gliricídia, corroborando com Gomide et al. (2002) que comentaram que a remoção da parte aérea, pelo corte ou pastejo, representa um estresse para as plantas, cuja magnitude depende da intensidade e da frequência da desfolha.

\section{CONCLUSÃO}

A frequência de corte de 90 dias e altura de resíduo de $90 \mathrm{~cm}$ proporciona melhores taxas de crescimento e maior produção de massa de folha e caule de forragem de gliricídia nas condições estudadas.

\section{AGRADECIMENTOS}

Ao Conselho Nacional de Pesquisa e Desenvolvimento (CNPq), pelo financiamento do projeto.

\section{BIBLIOGRAFIA}

Barreto, A.C. e Fernandes, M.F. 2001. Cultivo de Gliricidia sepium e Leucaena leucocephala em alamedas visando à melhoria dos solos dos tabuleiros costeiros. Pesqui Agropecu Bras, 36: 1287-1293.

Benincasa, M.M.P. 2003. Departamento de biologia aplicada à agropecuária. Análise de crescimento de plantas (noções básicas). FCAVUNESP. Jaboticabal.

Chaves, R.A.; Reis, M.das G.F.; Reis, G.G.; Pezzopane, J.E.M.; Xavier, A. e Monte, M.A. 2007. Dinâmica de cobertura de dossel de povoamento de clone de Eucalyptus grandis W. Hill ex-Maiden submetidos a desrama artificial a desbaste. Rev Árvore, 31: 989-998.

Costa, N.L.; Paulino, V.T.; Magalhães, J.A.; Townsend, C.R. e Pereira, R.G.A. 2008. Morfogênese de gramíneas forrageiras na Amazônia Ocidental. PUBVET, 2: 285.

Costa, B.M.da.; Santos, I.C.V.; Oliveira, G.J.C. e Pereira, I.G. 2009. Avaliação de folhas de Gliricidia sepium (JACQ.) Walp por ovinos. Arch Zootec, 58: 33-41.

Drumond, M.A. e Carvalho Filho, O.M. 1999. Introdução e avaliação de Gliricidia sepium na região semi-árida do Nordeste Brasileiro. Quéiroz, M.A. et al. (ed.) Recursos genéticos e melhoramento de plantas para o Nordeste brasileiro. Versão 1.0. Petrolina. Embrapa Semi-Árido. Brasília, DF. Embrapa Recursos Genéticos e Biotecnologia, nov. http://www.cpatsa.embrapa.br.

Fernandes, L.de O.; Reis, R.A. e Paes, J.M.V. 2010. Efeito da suplementação no desempenho de bovinos de corte em pastagem de Brachiaria brizanhta cv. Marandu. Ciênc Agrotec, 34: 240-248.

Ferreira, D.F. 2011 . Sisvar: um sistema computacional de análise estatística. Ciênc Agrotec, 35: 1039-1042.
Fisher, M. J. and Cruz, P. 1994. Some ecophysiological aspects of Arachis pintoi. Kerridge, P.C. and Hardy, B. (Ed.) Biology and Agronomy of forage Arachis. Centro Internacional de Agricultura Tropical (CIAT). Cali. CIAT. pp. 53-70.

Gama, T.C.M.; Zago, V.C.P.; Nicodemo, M.L.F.; Laura, V.A.; Volpe, E. e Morais, M.G. 2009. Composição bromatológica, digestibilidade in vitro e produção de biomassa de leguminosas forrageiras lenhosas cultivadas em solo arenoso. Rev Bras Saúde Prod Anim, 10: 560-572.

Gomide, C.A.M.; Gomide, J.A.; Huaman, C.A.M. e Paciullo, D.S.C. 2002. Fotossíntese, reservas orgânicas e rebrota do capim-mombaça (Panicum maximum Jacq.) sob diferentes intensidades de desfolha do perfilho principal. Rev Bras Zootecn, 31: 2165-2175.

Kanieski, M. R.; Santos, T.L.; Neto, J.G.; Souza, T.; Galvão, F. e Roderian, C.V. 2012. Influência da precipitação e da temperatura no incremento Diamétrico de Espécies Floreastais Aluviais em Araucária-PR. Revista Floresta Ambient, 1: 17-25.

Lopes, W.B.; Silva, D.S.; Pimenta Filho, E.C.; Silva, R.L. e Dias, J.M.Q. 2000. Avaliação morfofisiologica da leucena (Leucaena leucocephala) submetida a dois espaçamentos em duas épocas. Rev Bras Saúde Prod Anim, 2: 131-140.

Morales, B.J.E.M. 1996. Substitución del alimento concentrado por Ipomoea batatas L., Gliricidia sepium em becerros lactantes doble propósito. Informe Anual IPA 1994-1995. UCV. Facultad de Agronomia. Maracay. 32- 33.

Mororó, D.L.; Araujo Junior, L.M.; Pause, A.G.S. e Maneschyet, R.Q. 2010. Implantação de banco forrageiro com leguminosa herbácea em unidade de produção familiar. Agroecossistemas, 2: 53-59.

Noy-Meir, I. 1973. Desert ecosystems: environment and producers. Annu Rev Ecol Evol Syst, 4: 25-51.

Oliveira, M.A.; Pereira, O.G.; Gomide, J.A.; Huaman, C.A.M.; Garcia, R. e Cecon, P.R. 2000. Análise de crescimento do capim-bermuda 'Tifton 85' (Cynodon spp.). Rev Bras Zootecn, 29 (Supl. 1): 1930-1938.

Parsons, A.J. and Chapman, D.F. 2000. The principles of pasture growth and utilization. In: Hopkings, A. (ed.). Grass: it's production and utilization. Oxford: Blackwell Science. 31-88.

Peixoto, C.P.; Cruz, T.V.da. e Peixoto, M. de F. da S.P. 2011. Análise quantitativa do crescimento de plantas: Conceitos e prática. Encicl Biosf, 7: 51-76.

Perez, S.C.J.G.A. e Fanti, S.C. 1999. Crescimento e resistência à seca de leucena em solo de cerrado. Pesqui agropecu bras, 34: 933-944.

Pilau, A.; Rocha, M.G.; Restle, J.; Freitas, F.K. e Roso, D. 2005. Produção de forragem e produção animal em pastagem com duas disponibilidades de forragem associadas ou não à suplementação energética. Rev Bras Zootecn, 34: 1130-1137.

Speedy, A. and Pugliese, P. 1991. Legume trees and other fodder trees as protein sources for livestock. FAO Animal Production and Health. Paper 102. FAO. Rome.

Suassuna, J.M.A.; Santos, E.M.; Oliveira, J.S.de.; Azevedo, P.S.; Sousa, W.H.; Pinho, R.M.A.; Ramos, J.P. de F. and Bezerra, H.F.C. 2014. Carcass characteristics of lambs fed diets containing silage of different genotypes of sorghum. Rev Bras Zootecn, 43: 80-85.

Watson, D.J.; Wilson, J.H.; Ford, A.M. and French, S.A.W. 1966. Changes with age in the photosynthetic and respiratory components of the net assimilation rates of sugar beet and wheat. New Phytol, 65: 500-508. 